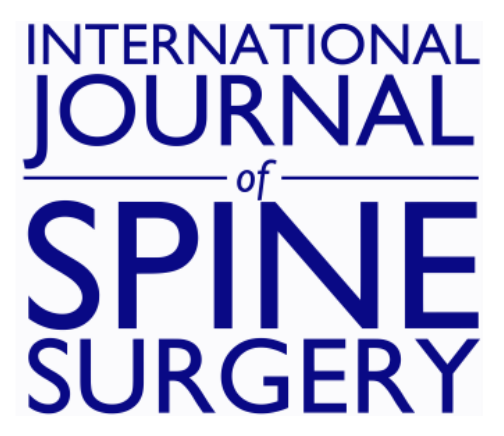

\title{
Primary Aneurysmal Bone Cyst of the Spine in Children: Updated Outcomes of a Modern Surgical Technique
}

\author{
EMMANOUIL GRIGORIOU, JOHN P. DORMANS and ALEXANDRE ARKADER
}

Int J Spine Surg 2020, 14 (4) 615-622

doi: https://doi.org/10.14444/7082

http://ijssurgery.com/content/14/4/615

This information is current as of April 26, 2023.

Email Alerts Receive free email-alerts when new articles cite this article. Sign up at:

http://ijssurgery.com/alerts 


\title{
Primary Aneurysmal Bone Cyst of the Spine in Children: Updated Outcomes of a Modern Surgical Technique
}

\author{
EMMANOUIL GRIGORIOU, MD, ${ }^{1,3}$ JOHN P. DORMANS, MD, ${ }^{2}$ ALEXANDRE ARKADER, MD ${ }^{1}$ \\ ${ }^{I}$ Department of Orthopaedic Surgery, Children's Hospital of Philadelphia, Philadelphia, Pennsylvania, ${ }^{2}$ Department of Orthopaedic Surgery, Riley Children's \\ Hospital, Indianapolis, Indiana, ${ }^{3}$ Department of Orthopaedic Surgery, University at Buffalo, Buffalo, New York
}

\begin{abstract}
Objective: Aneurysmal bone cysts $(\mathrm{ABC})$ are benign but locally aggressive lesions. Treating children with spinal $\mathrm{ABC}$ poses risks due to the proximity of the lesion to the spinal cord and the need to preserve spinal stability after surgery. This study reports the updated outcomes of a uniform aggressive initial surgical technique for the treatment of spinal $\mathrm{ABC}$ in children.

Methods: Twenty-nine cases of spinal ABC were collected from a tertiary pediatric tumor center over a 24-year period (January 1990-September 2014). The study patients were divided into 2 groups based on the performed procedure: a traditional approach consisting of curettage and bone grafting (group 1) and a 4-step approach consisting of intralesional curettage, high-speed bur, electrocautery, and bone grafting (group 2).

Results: The study population was composed of 12 males and 17 females with a mean age of 12.2 years at the time of diagnosis and a mean postoperative follow-up of 4.03 years. Twenty-one patients underwent the 4-step approach, while 8 patients were treated with the traditional technique. The recurrence rate was $50 \%(4 / 8$ patients) with the traditional technique (group 1) and 19\% (4/21) in the 4-step technique (group 2) $(P=.164)$. Regardless of the technique used, the presence of sensory symptoms at the time of presentation was a statistically significant factor for recurrence $(P$ $=.016)$.

Conclusions: We suggest that addressing spinal $\mathrm{ABC}$ in pediatric patients with a 4-step approach is a safe technique that may decrease long-term recurrence and reoperation rates compared to the traditional technique of intralesional curettage and bone grafting.
\end{abstract}

Level of Evidence: 4.

Tumor

Keywords: tumors, spine, aneurysmal bone cyst, pediatric, children, bone cyst

\section{INTRODUCTION}

Primary aneurysmal bone cysts (ABC) are benign but locally aggressive lesions that represent approximately $1 \%$ of all primary bone tumors. Primary $\mathrm{ABC}$ of the spine accounts for up to $15 \%-20 \%$ of all primary spine tumors, and it usually presents in the second decade of life ${ }^{1-3}$ involving most commonly the posterior elements of the spine. ${ }^{3}$ Although some series report predilection for the lumbar spine, ${ }^{2-4}$ others report higher incidence on the cervical and thoracic spine ${ }^{5,6}$ or equal incidence in the thoracic and lumbar region. ${ }^{7,8}$ Their close proximity to the spinal cord and nerve roots, their potential locally aggressive nature causing bone expansion and destruction, as well as the risk for postoperative instability and deformity make $\mathrm{ABC}$ of the spine a unique clinical and surgical challenging lesion.
Treatment options for spinal $\mathrm{ABC}$ range from observation to serial arterial embolization to intralesional injection of ablating agents and/or grafting material to surgical resection..$^{2-4,6,9}$ Traditionally, $\mathrm{ABC}$ of the spine are managed surgically with curettage and bone grafting with or without arthrodesis and instrumentation..$^{2-4,6,8,10}$ The use of adjuvant therapy with electrocautery, high-speed burr, phenolization, or cryotherapy, although suggested by many authors in ABC of long bones, it is not routinely used in spinal ABCs given the proximity to major neural structures.

Recurrence of pediatric spinal ABC pose a significant surgical challenge as well as burden to the child and his or her family. Minimizing recurrence rates after the index surgery is extremely important. Most previous major studies do not report outcomes on a uniform surgical treatment approach, and the patient population consists of 
both adults and children. This article presents a continuation and the long-term follow-up of a previously described technique by the senior author in a larger number of patients. ${ }^{7}$ As a way to reduce rates of reoperation in pediatric spinal $A B C$, we reassess the outcomes of management of $\mathrm{ABC}$ of the spine with an aggressive, uniform surgical approach consisting of a 4-step approach of intralesional curettage, high-speed burr, electrocautery, and bone grafting along with selected instrumentation, and we investigated whether the addition of phenol to the 4step approach could improve clinical outcomes.

\section{MATERIALS AND METHODS}

The study was approved by our institution's institutional review board and included pathologyproven primary spinal $\mathrm{ABC}$ patients who were surgically treated in a tertiary pediatric tumor center over a 24-year period (January 1990-September 2014).

Cases were collected through querying of our billing department via ICD-9 coding, from the pathology department reports, from our institution's tumor registry, from the main author's personal surgical cards, and from the neurosurgery department's records. We included all children below age 18 with pathology-proven primary ABC of the spine who underwent surgical treatment. Twenty-nine patients met our inclusion criteria. Charts, operative records, radiographs, and advanced imaging were reviewed, and the following variables were documented: gender, age, time to presentation, motor-sensory deficits, location and size of the tumor, Enneking stage (latent, active, or aggressive), pathologic fracture, preoperative deformity (location and magnitude of curve), preoperative embolization, type of surgery (traditional versus 4-step approach, addition of phenol or not), type and levels of spinal instrumentation and fusion, blood loss, neuromonitoring changes, surgical complications, and presence of recurrence at follow-up visits and timing and treatment of it. The study patients $(\mathrm{n}=29)$ were divided into 2 groups based on the surgical procedure performed: traditional approach (group 1) versus 4-step approach (group 2), and the 4-step group was further subdivided into 2 subgroups based on the addition of phenol or not. In our institution, we have been performing exclusively the 4-step approach after 2000; the only exceptions after 2000 have been patients 28 and 29, who were operated on by the
Neurosurgery Service (see Table 1). Similarly, phenol was added in all cases performed after 2010 except patients 28 and 29 (see Tables 1 and 2). Spinal fusion and instrumentation was indicated and performed based on the intraoperative assessment of the amount of bone and soft tissue involved by the tumor and the likelihood of instability. Tables 1 and 2 summarize the cohort's basic demographic data, lesion characteristics, and immediate postoperation as well as the latest follow-up data.

\section{Statistical Methods}

Statistical analysis was done using IBM SPSS statistics software. Analysis of variance was used for continuous variables and $\chi^{2}$ test for categorical variables; $P<.05$ was considered as statistically significant.

\section{RESULTS}

The study cohort was composed of 12 males $(41 \%)$ and 17 females $(59 \%)$ with a mean age of 12.2 years (range 3.2-18.6) at the time of diagnosis and a mean postoperative follow-up of 4.03 years (mean 48.38 months, range 0.5-194 months).

Seven of the ABC were localized in the cervical region $(24 \%), 8$ in the thoracic region $(28 \%), 11$ the lumbar region $(38 \%)$, and 3 in the sacral region $(10 \%)$. The lesion was limited to the posterior elements of the spine in 13 patients $(45 \%)$ and presented extension to the anterior elements in 16 $(55 \%)$. Based on the Enneking staging system for benign tumors, 19 patients were stage II-active lesions $(66 \%)$, while 10 patients were stage IIIaggressive lesions $(34.5 \%)$.

Overall, the mean time to presentation from onset of symptoms was 15.8 weeks (range 1-73 weeks). Pain was the universal presenting symptom for all 29 patients; 9 patients $(31 \%)$ also reported radicular pain, and 8 patients $(28 \%)$ presented with paresthesias, $6(21 \%)$ with motor weakness, $1(3 \%)$ with clonus, $1(3 \%)$ with hyperreflexia, and $1(3 \%)$ with bladder changes. Seven patients $(24 \%), 2$ in group 1 and 5 in group 2, presented with some degree of spinal deformity at their initial visit (mean Cobb angle $13.70^{\circ}$, range $5^{\circ}-30^{\circ}$ ).

Preoperative embolization was performed in 3 $(38 \%)$ patients with the traditional approach and 5 patients $(24 \%)$ with the 4-step approach. Twentyone patients $(72 \%)$ underwent the 4-step approach, 
Table 1. Patients' demographic and surgical data.

\begin{tabular}{|c|c|c|c|c|c|c|c|c|c|c|c|}
\hline ID & Sex & Age & $\begin{array}{c}\text { Vertebral } \\
\text { Level }\end{array}$ & $\begin{array}{l}\text { Vertebral } \\
\text { Elements }\end{array}$ & 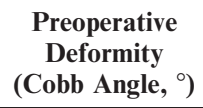 & Enneking & Surgery & $\begin{array}{l}\text { Blood } \\
\text { Loss } \\
(\mathrm{mL})\end{array}$ & $\begin{array}{l}\text { Spinal } \\
\text { Fusion }\end{array}$ & $\begin{array}{c}\text { No. of } \\
\text { Instrumented } \\
\text { Levels }\end{array}$ & $\begin{array}{l}\text { Postoperative } \\
\text { Complication }\end{array}$ \\
\hline 1 & $\mathrm{~F}$ & 15.9 & S2 & $\mathrm{P}$ & $\mathrm{N}$ & 2 & $\operatorname{Tr}$ & 600 & $\mathrm{~N}$ & 0 & $\mathrm{~N}$ \\
\hline 2 & M & 16.4 & $\mathrm{~T} 7$ & $\mathrm{P}$ and $\mathrm{A}$ & $\mathrm{N}$ & 3 & $\mathrm{Tr}$ & 900 & $\mathrm{~N}$ & 0 & Pain \\
\hline 3 & $\mathrm{~F}$ & 10.5 & $\mathrm{~T} 11$ & $\mathrm{P}$ and $\mathrm{A}$ & $\mathrm{N}$ & 2 & 4 & 700 & PSF* & 7 & $\mathrm{~N}$ \\
\hline 4 & $\mathrm{~F}$ & 18.6 & $\mathrm{C} 5$ & $\mathrm{P}$ & $\mathrm{N}$ & 2 & $4(\mathrm{PH})$ & 50 & $\mathrm{~N}$ & 0 & $\mathrm{~N}$ \\
\hline 5 & $\mathrm{M}$ & 7.5 & $\mathrm{C} 2$ & $\mathrm{P}$ and $\mathrm{A}$ & $\mathrm{N}$ & 3 & $\operatorname{Tr}$ & 150 & $\mathrm{~N}$ & 0 & $\mathrm{~N}$ \\
\hline 6 & $\mathrm{~F}$ & 13.2 & L5 & $\mathrm{P}$ and $\mathrm{A}$ & $\mathrm{N}$ & 2 & $\mathrm{Tr}$ & 100 & $\mathrm{~N}$ & 0 & Pain \\
\hline 7 & $\mathrm{~F}$ & 9.2 & L2 & $\mathrm{P}$ & $\mathrm{N}$ & 2 & 4 & 200 & $\mathrm{~N}$ & 0 & $\mathrm{~N}$ \\
\hline 8 & $\mathrm{~F}$ & 8.2 & T5 & $\mathrm{P}$ & $\mathrm{N}$ & 3 & 4 & 400 & PSF & 6 & SWI \\
\hline 9 & M & 15.7 & $\mathrm{~S} 1-\mathrm{S} 4$ & $\mathrm{P}$ & $\mathrm{N}$ & 2 & $4(\mathrm{PH})$ & 200 & $\mathrm{~N}$ & 0 & SWI \\
\hline 10 & M & 6.6 & L1 & $\mathrm{P}$ & Y (15) & 2 & 4 & 1300 & PSF & 5 & $\mathrm{~N}$ \\
\hline 11 & $\mathrm{~F}$ & 15.9 & L4 & $\mathrm{P}$ & $\mathrm{N}$ & 2 & 4 & 200 & PSF & 3 & Pain \\
\hline 12 & $\mathrm{~F}$ & 17.4 & $\mathrm{~T} 12$ & $\mathrm{P}$ and $\mathrm{A}$ & $\mathrm{N}$ & 2 & 4 & 850 & PSF & 3 & $\mathrm{~N}$ \\
\hline 13 & $\mathrm{~F}$ & 12.1 & C7 & $\mathrm{P}$ and $\mathrm{A}$ & $\mathrm{N}$ & 3 & 4 & 400 & PSF & 6 & Pain \\
\hline 14 & $\mathrm{M}$ & 9.4 & L4 & $\mathrm{P}$ & Y (11) & 3 & 4 & 700 & PSF* & 3 & $\mathrm{~N}$ \\
\hline 15 & M & 16.3 & $\mathrm{~T} 1$ & $\mathrm{P}$ & $\mathrm{N}$ & 3 & $4(\mathrm{PH})$ & 350 & PSF & 3 & $\mathrm{~N}$ \\
\hline 16 & M & 7.5 & S3-S4 & $\mathrm{P}$ and $\mathrm{A}$ & $\mathrm{N}$ & 3 & $4(\mathrm{PH})$ & 375 & $\mathrm{~N}$ & 0 & $\mathrm{~N}$ \\
\hline 17 & M & 10.0 & C6 & $\mathrm{P}$ and $\mathrm{A}$ & $\mathrm{N}$ & 2 & $4(\mathrm{PH})$ & 100 & PSF & 3 & $\mathrm{~N}$ \\
\hline 18 & M & 3.2 & L4 & $\mathrm{P}$ and $\mathrm{A}$ & Y (15) & 3 & 4 & 400 & PSF & 3 & $\mathrm{~N}$ \\
\hline 19 & M & 9.2 & $\mathrm{~L} 1$ & $\mathrm{P}$ and $\mathrm{A}$ & $\mathrm{N}$ & 2 & $4(\mathrm{PH})$ & 250 & PSF & 3 & $\mathrm{~N}$ \\
\hline 20 & $\mathrm{~F}$ & 12.3 & $\mathrm{C} 6-\mathrm{C} 7$ & $\mathrm{P}$ & $\mathrm{N}$ & 3 & $\operatorname{Tr}$ & 350 & $\mathrm{~N}$ & 0 & $\mathrm{~N}$ \\
\hline 21 & $\mathrm{~F}$ & 15.9 & L3 & $\mathrm{P}$ & Y (30) & 2 & $\operatorname{Tr}$ & 300 & PSF & 4 & $\mathrm{~N}$ \\
\hline 22 & $\mathrm{~F}$ & 17.7 & C5-C6 & $\mathrm{P}$ & $\mathrm{N}$ & 2 & $4(\mathrm{PH})$ & 800 & PSF & 5 & $\mathrm{~N}$ \\
\hline 23 & $\mathrm{~F}$ & 6.4 & $\mathrm{~T} 3$ & $\mathrm{P}$ and $\mathrm{A}$ & Y (14) & 2 & $4(\mathrm{PH})$ & 50 & PSF & 3 & Pain \\
\hline 24 & $\mathrm{~F}$ & 17.9 & $\mathrm{~T} 2$ & $\mathrm{P}$ & $\mathrm{N}$ & 2 & $4(\mathrm{PH})$ & 300 & PSF & 3 & $\mathrm{~N}$ \\
\hline 25 & $\mathrm{M}$ & 10.9 & L4 & $\mathrm{P}$ and $\mathrm{A}$ & $\mathrm{N}$ & 2 & $4(\mathrm{PH})$ & 800 & PSF & 3 & $\mathrm{~N}$ \\
\hline 26 & $\mathrm{~F}$ & 9.8 & $\mathrm{~T} 10$ & $\mathrm{P}$ and $\mathrm{A}$ & Y (6) & 2 & $4(\mathrm{PH})$ & 800 & PSF & 6 & Hemothorax \\
\hline 27 & $\mathrm{M}$ & 10.0 & C6 & $\mathrm{P}$ and $\mathrm{A}$ & $\mathrm{N}$ & 2 & $4(\mathrm{PH})$ & 350 & PSF & 3 & Scalp hematoma \\
\hline 28 & $\mathrm{~F}$ & 17.2 & L3 & $\mathrm{P}$ and $\mathrm{A}$ & Y (5) & 3 & $\operatorname{Tr}$ & 3500 & PSF & 3 & $\mathrm{~N}$ \\
\hline 29 & $\mathrm{~F}$ & 13.5 & T11 & $\mathrm{P}$ and $\mathrm{A}$ & $\mathrm{N}$ & 2 & $\mathrm{Tr}$ & 700 & PSF & 5 & $\mathrm{~N}$ \\
\hline
\end{tabular}

Abbreviations: 4, 4-step approach; 4(PH), 4-step process with phenol; A, anterior; C, cervical; F, female; L, lumbar; M, male; N, no; P, posterior; PSF, posterior spinal instrumentation; PSF*, anterior and posterior exposure with posterior instrumentation; S, sacral; SWI, superficial wound infection; T, thoracic; Tr, traditional approach; Y, yes.

while 8 patients $(28 \%)$ were treated with the traditional technique. The mean blood loss was $825 \mathrm{~mL}$ in group 1 and $455 \mathrm{~mL}$ in group $2(P>.05)$. Neuromonitoring was used in all index surgeries in both groups. There was 1 neuromonitoring change in each group; both patients had neurological deficits preoperatively, and neither patient had any residual deficits at latest follow-up. Twenty out of the total of 29 patients $(69 \%)$ had instrumentation at their first surgery. All patients underwent posterior instrumentation (group $1=3$ patients; group $2=17$ patients), even the 2 patients who underwent a combined anteroposterior approach to achieve wide local resection. The instrumentation included pedicle screws and cage constructs (2 patients) (Figure 1), sublaminar cables (7 patients) (Figure 2), hooks and rods (5 patients) (Figure 3) or rods and pedicle screws ( 3 patients), while 2 of the earlier patients underwent instrumentation with a Harrington rod. In the 12 patients who received phenol intraoperatively, no neurological complications were noted, and only 1 of the 12 patients developed a superficial wound infection postoperatively treated with oral antibiotics. One superficial wound infection was also noted in the 17 patients who did not receive phenol.

The overall recurrence rate for our cohort was $28 \%$ ( $8 / 29$ patients); the rate was $50 \%$ (4/8 patients) with the traditional technique and $19 \%(4 / 21)$ in group $2(P=.164)$. Regardless of the technique used, the presence of paresthesias at the time of presentation was a statistically significant factor in terms of recurrence rate $(P=.016)$. In the 4 -step group 2, 12/21 patients $(57 \%)$ who additionally received phenol had slightly lower recurrence rates $(17 \%)(P>.05)$. The mean time to recurrence was 4.9 months (range 1-14 months), 3 months with the traditional technique, and 6.8 months with the 4step technique. Six of the 8 recurrences $(75 \%)$ underwent revision surgery (all patients were treated with the 4-step approach at revision), 1 patient (patient 1) underwent 1 postoperative embolization for a recurrent S2 lesion, and 1 patient (patient 5) was managed conservatively with close observation with repeat imaging and had residual but stable $\mathrm{ABC}$ at the latest follow-up 8 years after his initial procedure. One patient (patient 13) underwent 2 subsequent revision surgeries (4-step technique) and 
Table 2. Patients' follow-up data.

\begin{tabular}{|c|c|c|c|c|c|c|}
\hline ID & Surgery & Recurrence & $\begin{array}{c}\text { Time to } \\
\text { Recurrence (mo) }\end{array}$ & $\begin{array}{l}\text { Deformity at } \\
\text { Latest FU }\left(^{\circ}\right)\end{array}$ & Latest FU & $\begin{array}{c}\text { Total Postoperative } \\
\text { FU (mo) }\end{array}$ \\
\hline 1 & $\operatorname{Tr}$ & $\mathrm{Y}$ & 4 & $\mathrm{~N}$ & Residual stable $\mathrm{ABC} /$ no symptoms & 36.87 \\
\hline 2 & $\operatorname{Tr}$ & $\mathrm{Y}$ & 3 & $\mathrm{~N}$ & $\mathrm{NED} /$ back pain & 43.47 \\
\hline 3 & 4 & $\mathrm{~N}$ & 0 & $\mathrm{Y}(<10)$ & NED/no symptoms & 121.03 \\
\hline 4 & $4(\mathrm{PH})$ & $\mathrm{N}$ & 0 & $\mathrm{~N}$ & NED/no symptoms & 6.00 \\
\hline 5 & $\operatorname{Tr}$ & $\mathrm{Y}$ & 2 & $\mathrm{~N}$ & Residual stable $\mathrm{ABC} /$ no symptoms & 104.90 \\
\hline 6 & $\operatorname{Tr}$ & $\mathrm{Y}$ & 3 & $\mathrm{~N}$ & NED/no symptoms & 47.97 \\
\hline 7 & 4 & $\mathrm{~N}$ & 0 & $\mathrm{~N}$ & NED/no symptoms & 88.73 \\
\hline 8 & 4 & $\mathrm{~N}$ & 0 & $\mathrm{Y}(<10)$ & NED/no symptoms & 194.13 \\
\hline 9 & $4(\mathrm{PH})$ & $\mathrm{N}$ & 0 & $\mathrm{~N}$ & NED/residual numbness right buttock & 81.57 \\
\hline 10 & 4 & $\mathrm{~N}$ & 0 & $\mathrm{~N}$ & NED/no symptoms & 91.50 \\
\hline 11 & 4 & $\mathrm{Y}$ & 14 & $\mathrm{Y}(<10)$ & NED/no symptoms & 37.57 \\
\hline 12 & 4 & $\mathrm{~N}$ & 0 & $\mathrm{Y}(<10)$ & NED/no symptoms & 71.07 \\
\hline 13 & 4 & $\mathrm{Y}$ & 4 & $\mathrm{~N}$ & Residual stable $\mathrm{ABC} /$ no symptoms & 103.80 \\
\hline 14 & 4 & $\mathrm{~N}$ & 0 & $\mathrm{Y}(<10)$ & NED/no symptoms & 96.13 \\
\hline 15 & $4(\mathrm{PH})$ & $\mathrm{N}$ & 0 & $\mathrm{~N}$ & NED/no symptoms & 6.87 \\
\hline 16 & $4(\mathrm{PH})$ & $\mathrm{Y}$ & 1 & $\mathrm{~N}$ & NED/no symptoms (resolved foot drop) & 4.90 \\
\hline 17 & $4(\mathrm{PH})$ & $\mathrm{N}$ & 0 & $\mathrm{~N}$ & NED/alopecia from the halo & 19.93 \\
\hline 18 & 4 & $\mathrm{~N}$ & 0 & $\mathrm{~N}$ & NED/no symptoms & 90.87 \\
\hline 19 & $4(\mathrm{PH})$ & $\mathrm{N}$ & 0 & $\mathrm{~N}$ & NED/no symptoms & 0.53 \\
\hline 20 & $\operatorname{Tr}$ & $\mathrm{N}$ & 0 & $\mathrm{~N}$ & Residual stable $\mathrm{ABC} /$ no symptoms & 59.17 \\
\hline 21 & $\operatorname{Tr}$ & $\mathrm{N}$ & 0 & $\mathrm{Y}(<10)$ & NED/no symptoms & 0.87 \\
\hline 22 & $4(\mathrm{PH})$ & $\mathrm{N}$ & 0 & $\mathrm{~N}$ & NED/no symptoms & 29.10 \\
\hline 23 & $4(\mathrm{PH})$ & $\mathrm{N}$ & 0 & $\mathrm{Y}(10)$ & Residual stable $\mathrm{ABC} /$ no symptoms & 14.13 \\
\hline 24 & $4(\mathrm{PH})$ & $\mathrm{N}$ & 0 & $\mathrm{~N}$ & NED/no symptoms & 7.53 \\
\hline 25 & $4(\mathrm{PH})$ & $\mathrm{Y}$ & 8 & Y (15) & Residual stable ABC/no Symptoms & 14.03 \\
\hline 26 & $4(\mathrm{PH})$ & $\mathrm{N}$ & 0 & $\mathrm{Y}(<10)$ & NED/no symptoms & 0.50 \\
\hline 27 & $4(\mathrm{PH})$ & $\mathrm{N}$ & 0 & $\mathrm{~N}$ & NED/no symptoms & 13.53 \\
\hline 28 & $\operatorname{Tr}$ & $\mathrm{N}$ & 0 & $\mathrm{Y}(<10)$ & $\mathrm{NED} /$ no symptoms & 14.73 \\
\hline 29 & $\operatorname{Tr}$ & $\mathrm{N}$ & 0 & $\mathrm{~N}$ & NED/no symptoms & 1.63 \\
\hline
\end{tabular}

Abbreviations: 4, 4-step approach; 4(PH), 4-step process with phenol; ABC, aneurysmal bone cyst; FU, follow-up; N, no; NED, no imaging evidence of disease; Tr, traditional approach; Y, yes.

postoperative embolizations (total of 3 procedures and 3 embolizations) and still presented with residual but stable $\mathrm{C} 7 \mathrm{ABC}$ at the latest follow-up 8.5 years after her first procedure.

Overall, at latest follow-up, 1 patient had continued back pain (without radiographic evidence of disease recurrence), and 1 patient had residual buttock numbness similar to his preoperative symptom; all 6 patients who had residual $A B C$ noted on imaging at latest follow-up did not have any clinical symptoms.

\section{DISCUSSION}

Previous studies of primary spinal $\mathrm{ABC}$ in children encompassed very long periods of time and described outcomes of multiple various different treatment modalities on a population consisting of adults and children. ${ }^{2,4-6,11}$ We present a continuation of our previous study ${ }^{7}$ with a larger number of patients (29 instead of 12) and longer follow-up on the previously reported patients to carefully and uniformly access the outcomes of management of $A B C$ of the spine treated with an aggressive approach. Minimizing recurrence rates after the index surgery is extremely important; recurrent
ABC can be very difficult to manage, resulting in local neurological as well as surgical impairment and posing a significant burden to the child as well as his or her family. For this reason, we believe that identifying an appropriate index treatment that decreases recurrence rates is crucial for the treatment of these locally aggressive lesions. As described in our previous study, the senior author's preferred 4-step treatment regimen for $\mathrm{ABC}$ of the spine uses curettage, high-speed bur, electrocautery, and bone grafting. Routinely in all cases, prior to this regimen, an intraoperative frozen section is taken and examined in conjunction with the pathologist to confirm the diagnosis ${ }^{7}$.

Our current data agree with previously reported data in the literature regarding the predilection of these lesions for the lumbar spine, ${ }^{2-4}$ the involvement of the posterior elements of the spine, and the Enneking staging at presentation (all lesions are stage 2 or 3). 2,4,8,10,11 Given the locally aggressive nature of these lesions, wide exposure for excellent visualization is mandatory; loupe magnification, a surgical headlamp, and a wide surgical exposure are always used to obtain excellent visualization of the lesion before initiating surgical excision (Figure 3). 


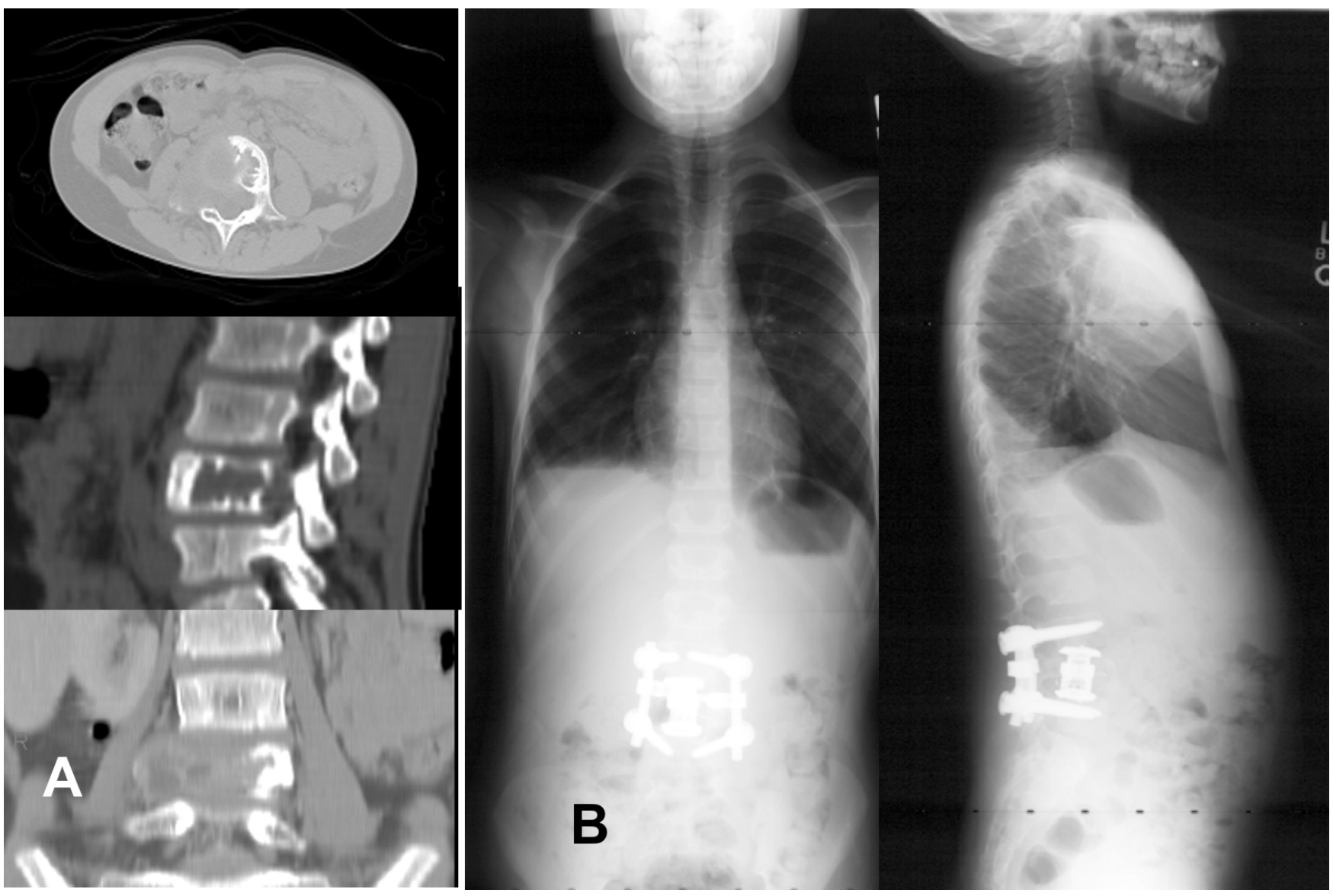

Figure 1. Patient 14, 9-y-old male, presenting with right lower extremity radicular-type pain and an L 4 vertebral body aneurysmal bone cyst measuring $2.2 \times 4.7 \times 4$ $\mathrm{mm}$. (A) Preoperative axial, coronal, and sagittal computed tomography showing the expanding L4 vertebral body lesion with extension to and obliteration of the right pedicle. (B) Patient underwent a 4-step approach, L3-L5 instrumentation, and L4 vertebral cage. Patient was asymptomatic without clinical or radiographic evidence of recurrence at latest follow-up 8 y later at 17 y old.

As advocated in our previous study, a posterior surgical approach is most commonly appropriate as long as wide enough exposure for excellent visualization of the lesion is achieved or unless there is extensive involvement of the vertebral body. A posterior-only approach was utilized in all cases except 2, where the extent of the tumor dictated a combined anterior and posterior approach to achieve local control. Appropriate preoperative planning and wide exposure also minimize the need for intraoperative advanced imaging during excision.

The recurrence rates of surgical treatment of primary spinal $\mathrm{ABC}$ in children vary in the literature, ranging from $5 \%$ to $70 \%$ with most studies reporting rates around $10 \%-25 \%{ }^{4,6,8,10}$ Although we were able to show a clear trend $(50 \%$ recurrence rate $[4 / 8$ patients] with the traditional technique and $19 \%$ [4/21] with the 4-step technique $(P=.164)$, unfortunately the small number of patients did not allow us to show statistical significance. The addition of phenol resulted in slightly lower recurrence rates $(17 \%)$ than in group 2 without statistical significance. Finally, no statistical difference was noted in terms of recurrence rates and Enneking staging system or instrumentation. Fifty percent of the recurrences ( $4 / 8$ patients) were Enneking stage 2, and $50 \%$ were stage 3 at presentation. From the total of 8 patients who recurred, 5 did not have any kind of instrumentation at the index surgery, while 3 were instrumented. In our institution, our approach to patients with a recurrence is to perform a repeat 4-step approach.

In 8 patients $(28 \%)$, preoperative embolization was used prior to the initial surgery to reduce intraoperative bleeding. Although preoperative embolization might be a useful tool when it can be safely performed, we do not believe that its routine use is necessary or should be the standard of care; each case should be individually assessed based on the characteristics of the lesion and the patient. ${ }^{8,10}$ Selective arterial embolization of spinal $\mathrm{ABC}$ has 

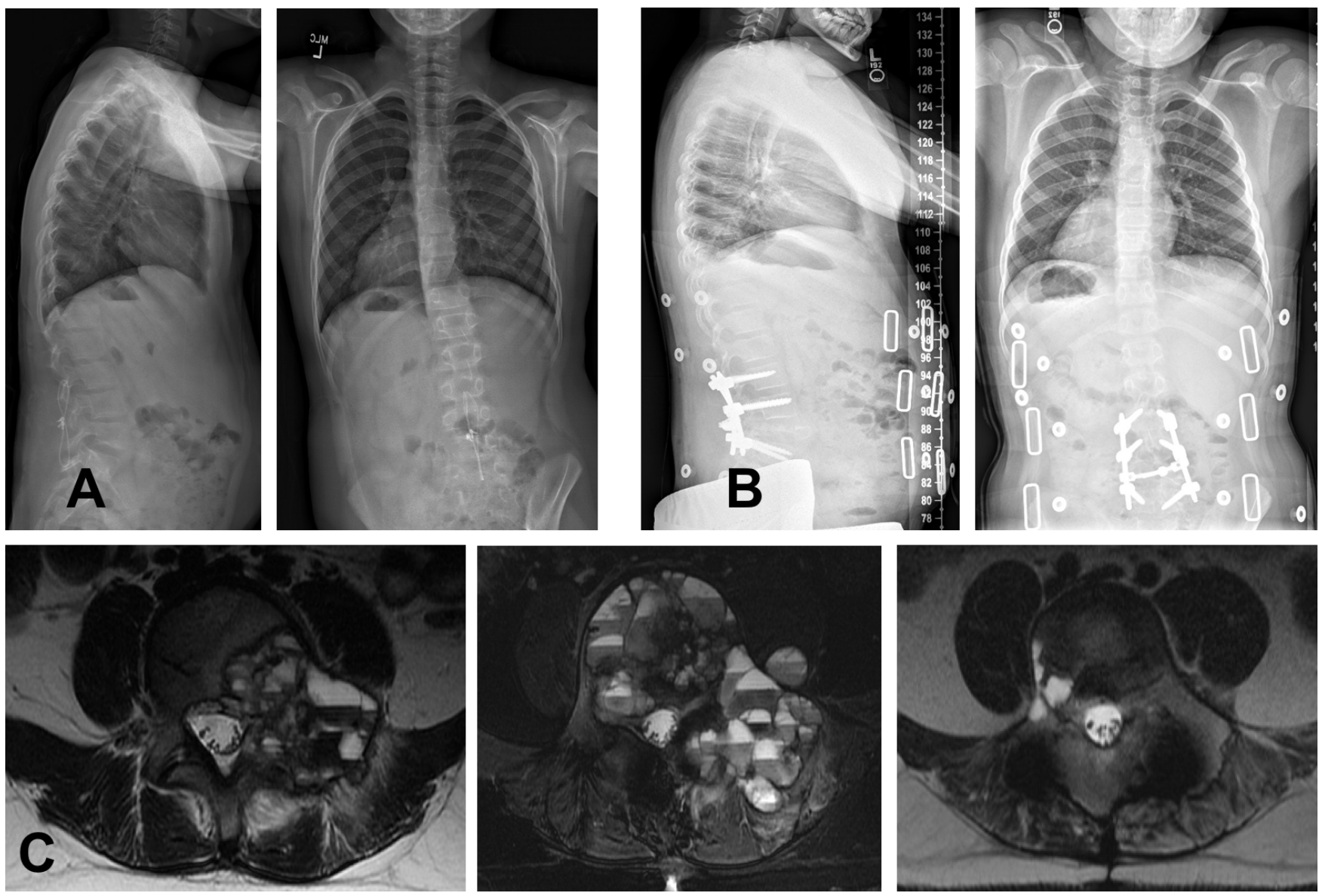

Figure 2. Patient 25, an 11-y-old male, presenting with an extensive aneurysmal bone cyst (measuring $4.6 \times 5.2 \times 5.3 \mathrm{~mm}$ ) involving the posterior elements of L3-L5 and the vertebral body of $\mathrm{L} 4$ with almost complete vertebral body obliteration and collapse. Patient had radicular pain on the left lower extremity at presentation. (A) Initially, patient underwent a 4-step approach and stabilization with a sublaminar L3-L5 cable via a posterior approach; however, 8 mo after the index procedure, he presented with significantly increased pain and radiographic evidence of recurrence. (B) Patient underwent a repeat 4-step approach and L2-L5 instrumentation with pedicle screws. At latest follow-up, patient was asymptomatic clinically, had evidence of residual but stable disease, and is currently being closely followed with repeat imaging. (C) Axial and sagittal magnetic resonance imaging cuts depicting the progression of the lesion from preoperative (far left) to recurrence (middle) to latest postoperative (far right) status after repeat 4-step approach. Note the interval size increase and collapse of the L4 vertebral body at the time of recurrence.

been proposed in the literature both as a preoperative adjunct to surgery and a definitive treatment. The data in the literature are very limited, especially in the pediatric population, and there is no clear evidence that they actually lead to decreased intraoperative blood loss or overall better functional outcomes and decreased recurrence rates. Several groups have expressed concerns about the role of serial arterial embolization in spinal ABC due to the shared collaterals between the spinal cord and the $\mathrm{ABC}$; especially concerning are lesions in the thoracolumbar spine with involvement of the artery of Adamkiewicz or in the cervical spine due to the association with the vertebral arteries. ${ }^{4,6,12}$ In our series, only 2 patients received preoperative embolization after 2005; both these patients were operated on by the neurosurgery team. With the advances in surgical techniques, the senior author has not felt it necessary to include preoperative embolization in the treatment plan in any patients after 2005. In our experience, usually there are only a few well-defined intrinsic (feeder) arteries, and the shared collaterals with the spinal cord limit the actual number of vessels that can be safely embolized. Additionally, although complications with selective arterial embolization appear to be rare, catastrophic inadvertent episodes have been described. ${ }^{13}$ Additionally, embolization as a method of definitive treatment has little role in cases of spinal cord compression and instability, where timing and stabilization of the spine are crucial.

The main limitation of our study is its retrospective nature and the inherently associated risks and biases. Additionally, as expected when dealing with surgical results of uncommon tumors in children, this study was limited by the small number of cases. The relatively low incidence of primary spinal ABC in children provides challenges in drawing concrete 


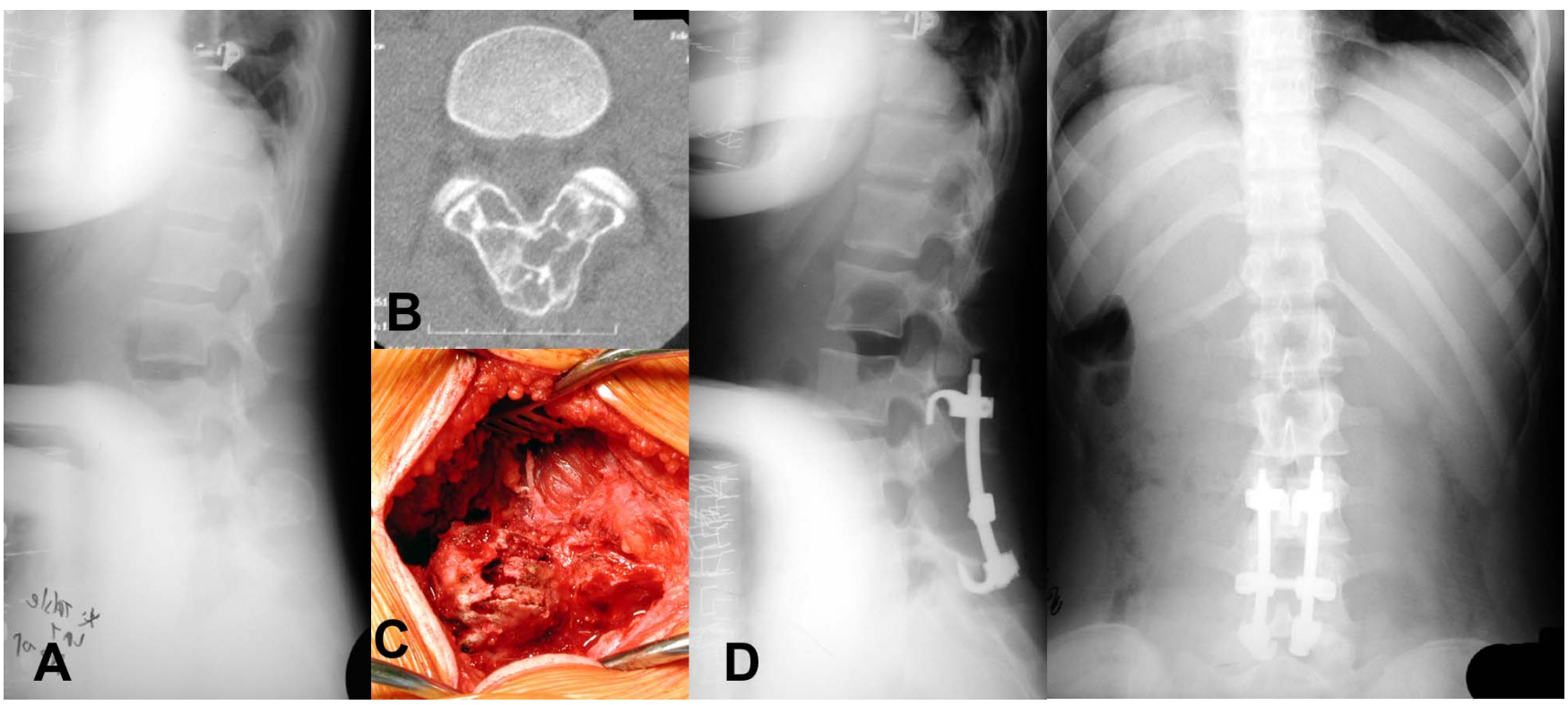

Figure 3. Patient 11. Preoperative lateral radiograph (A), axial computed tomography (B), intraoperative picture (C), and postoperative lateral and anteroposterior radiographs (D). This 16-y-old female presented with an expanding L4 aneurysmal bone cyst limited to the posterior elements and underwent a 4-step approach and subsequent L3-L5 instrumentation with a hook and rod construct.

conclusions in terms of survival and recurrence rates from the data of a single institution; we believe that a larger multicenter and prospective study is needed to potentially identify the standard of care for these tumors. Another limitation of the study is the lack of at least 2 years of follow-up in all patients. Similar to the data reported in the literature, most recurrences occurred within the first year postoperatively. ${ }^{7,8,10}$ In the current series, $90 \%$ of recurrences $(7 / 8$ patients) occurred within the first year, and $75 \%$ of recurrences $(6 / 8$ patients) occurred within the first 6 months. For this reason, we felt that we should not include only patients with more than 1 or 2 years of follow-up, as we would have missed recurrences.

In conclusion, we propose that addressing spinal $\mathrm{ABC}$ in pediatric patients with a 4-step approach of intralesional curettage, high-speed bur, electrocautery, and bone grafting (with or without phenol) is a safe technique that may decrease long-term recurrence and reoperation rates compared to the traditional technique of intralesional curettage and bone grafting.

\section{REFERENCES}

1. Cottalorda J, Kohler R, Sales de Gauzy J, et al. Epidemiology of aneurysmal bone cyst in children: a multicenter study and literature review. $J$ Pediatr Orthop $B$. 2004;13(6):389-394.

2. Capanna R, Albisinni U, Picci P, Calderoni P, Campa- nacci M, Springfield DS. Aneurysmal bone cyst of the spine. $J$ Bone Jt Surg Am. 1985;67(4):527-531.

3. Hay MC, Paterson D, Taylor TK. Aneurysmal bone cysts of the spine. J Bone Jt Surg Br. 1978;60-B(3):406-411.

4. Boriani S, De Iure F, Campanacci L, et al. Aneurysmal bone cyst of the mobile spine: report on 41 cases. Spine (Phila Pa 1976). 2001;26(1):27-35.

5. Vergel De Dios AM, Bond JR, Shives TC, McLeod RA, Unni KK. Aneurysmal bone cyst. A clinicopathologic study of 238 cases. Cancer. 1992;69(12):2921-2931.

6. Papagelopoulos PJ, Currier BL, Shaughnessy WJ, et al. Aneurysmal bone cyst of the spine. Management and outcome. Spine (Phila Pa 1976). 1998;23(5):621-628.

7. Garg S, Mehta S, Dormans JP. Modern surgical treatment of primary aneurysmal bone cyst of the spine in children and adolescents. JPediatr Orthop. 2005;25(3):387-392.

8. Zenonos G, Jamil O, Governale LS, Jernigan S, Hedequist D, Proctor MR. Surgical treatment for primary spinal aneurysmal bone cysts: experience from Children's Hospital Boston. J Neurosurg Pediatr. 2012;9(3):305-315.

9. Sebaaly A, Ghostine B, Kreichati G, et al. Aneurysmal bone cyst of the cervical spine in children: a review and a focus on available treatment options. J. Pediatr Orthop. 2015;35(7):693-702.

10. Boriani S, Lo SF, Puvanesarajah V, et al. Aneurysmal bone cysts of the spine: treatment options and considerations. $\mathrm{J}$ Neurooncol. 2014;120(1):171-178.

11. de Kleuver M, van der Heul RO, Veraart BE. Aneurysmal bone cyst of the spine: 31 cases and the importance of the surgical approach. J Pediatr Orthop B. 1998;7(4):286292.

12. Ozaki T, Halm H, Hillmann A, Blasius S, Winkelmann W. Aneurysmal bone cysts of the spine. Arch Orthop Trauma Surg. 1999;119(3-4):159-162.

13. Turowski B, Schellhammer F, Herdmann J, Rommel F. Fatal Ethibloc embolization of vertebrobasilar system following 
percutaneous injection into aneurysmal bone cyst of the second cervical vertebra. Am J Neuroradiol. 2005;26(7):1883-1884.

Disclosures and COI: The authors received no funding for this study and report no conflicts of interest. The study was approved by our institution's institutional review board.

Corresponding Author: Alexandre Arkader, MD, Children's Hospital of Philadelphia, Perelman School of Medicine at University of Pennsylvania,
Philadelphia, PA 19104-4399. Phone: (215) 5901527; Fax: (215) 590-1500; Email: arkadera@email. chop.edu.

Published 28 August 2020

This manuscript is generously published free of charge by ISASS, the International Society for the Advancement of Spine Surgery. Copyright (C) 2020 ISASS. To see more or order reprints or permissions, see http://ijssurgery.com. 